\title{
Standard Series of Multispeed Mechanical Transmissions with Automatic Control for Advanced Trucks
}

\author{
Aleksandr Blokhin*, Lev Barakhtanov, Arcady Nedyalkov, Alla Koshurina and Aleksandr Taratorkin \\ Transport systems institute, Nizhny Novgorod State Technical University named after. R.E. Alekseev, Nizhny Novgorod, Russian \\ Federation \\ *Corresponding author
}

\begin{abstract}
The paper considers the main criteria for establishing advanced unified standard series of mechanical transmissions. It presents the development of the entire standard series of advanced manual transmission with automatic control with a number of gears from 6 to 16. It considers features of structures produced on the basis of innovative technical solutions. It presents the results of experimental studies and the results of comparison of theoretical and computational data for the gearshift time.
\end{abstract}

Keywords-multi-stage transmission; pneumatic actuator; synchronization process; automatic control; command control

\section{TRENDS OF DEVELOPMENT OF MANUAL TRANSMISSIONS}

The transmissions of vehicles around the world most often have multispeed mechanical synchronized gearboxes with a friction clutch having such advantages as small weight and size, high reliability and service life, low cost, high energy performance as well as ease of maintenance and repair.

For the majority of trucks and road trains multispeed gearboxes are widely used. Their use ensures high traction and speed, reduced fuel consumption and improved environmental properties. Such gearboxes can be rationally used with automatic and command (semi-automatic) control, which allows us to realize the benefits of a wide range of gear ratios, creates a more comfortable environment for the driver and improves traffic safety.

The main trends in the development of modern manual transmissions are as follows $[1,2]$ :

1. Increase the density of ratios in the entire range of the gearboxes, which primarily takes place in the gear boxes of trucks and super heavy-duty vehicles.

2. Increase the range of ratios defining the limits of traction and speed characteristics of the vehicle. This allows to increase the traction of the vehicle or the road train and to reduce the slipping clutch operation at the same time, thereby increasing the reliability and longevity of its operation.

3. Adoption of new structural schemes of gearboxes, allowing to provide the required number of gears. This is achieved using multispeed gearboxes having a relatively small number of gear wheels and additional driving pairs of them in front of the main gear unit (splitter) or planetary synchronized range gear installed behind the main gear unit, or through the use of the so-called hybrids, including both the front splitter, and the planetary range gear.

4. The use of new design of compact energy-synchronizers using molybdenum covered friction cones, including doublecone ones.

5. The trend of setting gears on the shafts on needle bearings in the separators, which can significantly increase the speed mode of the gearbox, and improve the aligning of the gears on the shafts. This constructive solution in combination with a lubricant under pressure, which is especially necessary for heavy gearboxes, provides a guaranteed reliable operation of the unit.

6. The increasing use of the automated clutch control and gear shifting. Almost all well-known companies, such as, ZF, Volvo, Mercedes-Benz, Scania, Renault, Eaton et al. establish a full-time or on-demand automated electro-pneumatic gearbox control.

7. We can see a trend of sharp increase of the engine torques while significantly increasing of the requirements to gearboxes for resources.

Creation of the units corresponding to these requirements demands a lot of experimental work related to the utmost optimization of each element of the gearbox. The created promising gearboxes should have simple design solutions, proven tests and they should surpass in the output parameters the best-known analogues of leading companies in the field of transmissions.

\section{CHARACTERISTICS OF TRANSMISSIONS OF STANDARD SERIES}

Taking into consideration the current trends of development and applying forward-looking solutions the specialists of the NNSTU and the COM Group (Russia, Naberezhnye Chelny, http://komgroup.ru) developed a standard series of advanced mechanical transmissions for cars, road trains and heavy trucks for engines ranging from 75 to $750 \mathrm{~kW}$ (100 to $1000 \mathrm{HP}$ ) in a range of torques from 360 to $3500 \mathrm{Nm}$. Standard series (Table 1) includes five basic sizes of transmissions, three of which are 6-speed and two - multispeed, 8 and 16 speed gearboxes. The 8 -speed gearbox consists of two gear units connected in one crankcase: from the basic 4-speed crankcase and 2-speed one. 
Execution of works [1-5] included the creation of original calculation methods, the development of design, prototyping, development of special test methods and carrying out bench, resource and functional tests, finishing the design on the basis of the test results and release of drawing documentation for preparation of the serial production. By the number of transmissions of synchronized steps, the transmitted maximum torque and power, the range and density of a number of gear ratios the gearbox of standard series correspond to modern best analogues, in particular, such well-known ones as ZF, Volvo, Eaton, Mercedes-Benz, Scania, Renault. In addition, for all multispeed gearboxes we developed original friction clutch control mechanism shown in the works [6].

TABLE I. BASIC PARAMETERS OF STANDARD SERIES OF ADVANCED GEARBOXES

\begin{tabular}{|c|c|c|c|c|c|c|c|}
\hline $\begin{array}{c}\text { Mo } \\
\text { difi } \\
\text { cati } \\
\text { ons }\end{array}$ & $\begin{array}{c}\text { Designation of } \\
\text { the gearbox }\end{array}$ & $\begin{array}{c}\text { Input } \\
\text { point } \\
\text { Nm }\end{array}$ & $\begin{array}{c}\text { Num } \\
\text { ber } \\
\text { of } \\
\text { gear } \\
\text { s }\end{array}$ & Range & $\begin{array}{c}\text { Axle size } \\
\text { on the } \\
\text { ends of } \\
\text { crankcase, } \\
\text { mm }\end{array}$ & $\begin{array}{c}\text { Cente } \\
\mathbf{r} \\
\text { distan } \\
\text { ce, } \\
\text { mm }\end{array}$ & keight, \\
kg \\
\hline 1 & M6-300 & 360 & 6 & 9,25 & 295 & 100 & 51,5 \\
\hline 2 & M6-700 & 750 & 6 & 9,10 & 380 & 135 & 120 \\
\hline 3 & M6-1100 & 1300 & 6 & 9,10 & 460 & 165 & 205 \\
\hline 4 & TM8-1300 & 1650 & 8 & 12,38 & 460 & 135 & 160 \\
\hline 5 & TM8-2000/1 & 2200 & 8 & 13,77 & 485 & 170 & 245 \\
\hline 6 & TM8-2700/2 & 2700 & 8 & 13,77 & 485 & 170 & 245 \\
\hline 7 & TM8-3500 & 3500 & 8 & 14,16 & 520 & 170 & 275 \\
\hline 8 & TM12-1800/1 & 1800 & 12 & 15,05 & 500 & 170 & 270 \\
\hline 9 & TM12-2200/2 & 2200 & 12 & 15,15 & 500 & 170 & 270 \\
\hline 10 & TM16-2000 & 2200 & 16 & 17,04 & 570 & 170 & 300 \\
\hline 11 & TM16-3000 & 3000 & 16 & 16,87 & 570 & 170 & 300 \\
\hline 12 & TM16-3500 & 3500 & 16 & 16,87 & 615 & 170 & 325 \\
\hline
\end{tabular}

In table 1 the weight of the gearbox is shown without the clutch case. Index / 1 - refers to the modification of the gearbox with a higher direct transfer. Index / 2 - refers to the modification with the higher overdrive. The TM index means that the kinematic scheme of a mechanical gearbox includes the main gear formed according to the three-shaft design, with the planetary range gear.

\section{FEATURES OF THE DEVELOPED GEARBOX}

Positive features of three types of sex-staged gearboxes, covering nearly 4 times the torque range - from 360 to 1300 $\mathrm{Nm}$, are as follows [2]:

- Axial dimensions, internal loss and weight of the gearboxes are located within 5-speed gearboxes or less. A wide range of gear ratios eliminates the necessity of splitters in the transfer gearbox for such vehicles as "Jeep" and other allterrain vehicles, that simplifies and reduces the cost of the transmission unit;

- A single, unified system of automated electro-pneumatic control;

- A reduction in fuel consumption due to low internal losses and wide ratio coverage of the gearboxes.

For the whole family of the TM model of the multispeed gearboxes, two of which - TM8-1300 and TM 16-2000 are basic sizes and 9 modifications (taking into account the possibility of application of the highest transmission both direct and accelerating that at the extremely low cost expands the use of multispeed transmissions for a variety of engines and operating conditions of cars and trucks), were manufactured for the first time in the world with the use of a very simple threeshaft kinematic scheme without any additional supports and parasitic components when there are just three shafts, four supports and two crankcase parts. This allowed us to have an axial dimension of the base gearbox TM162000 $85 \mathrm{~mm}$ less compared to the same ZF gearbox (model - Astronic 16AS 2200), although the latter has 2 intermediate shafts and a lower load-bearing capacity, which when converted to an equivalent load bearing capacity increases the difference in the axial envelope from 85 to $133.5 \mathrm{~mm}$ and this is without difference of $20 \mathrm{~mm}$, due to the installation into the gearbox of two toothed couplings instead of the synchronizers. Thus, with the same functional capabilities the difference in the axial envelope reaches to $153.5 \mathrm{~mm}$ in favor of transmission TM16-2000. This, in particular, is one of the important indicators of the positive distinguishing features of the advanced technical level of the design solutions.

Small axial dimensions and mass parameters of the gearboxes even when with their relatively overestimated bearing capacity allows us to use the unit with a relatively small engine torque, because eventually the lowest limit of the use of the gearbox is determined by its dimensional and weight parameters. Small weight of the gearbox allows you to have a smaller number of sizes and, therefore, more mass production, which will help to reduce the cost of the unit

At the same time we solved the problem of reducing of internal losses in gearboxes due to their original design, geometric and kinematic features. The internal losses in the gearbox TM16-2000 make $1.3 \mathrm{~kW}$ against $2.65 \mathrm{~kW}$ in a similar gearbox ZF S16-220 (based on the results of the ZF Company on measuring mode - direct transmission at 2000 min-1.).

The main features of multispeed designs (8-12) of the gearboxes of the developed standard series are as follows [1, 4]:

1. When designing the gearboxes we used the so-called modular principle, according to which the gearbox is made from functionally independent units and mechanisms, as opposed to the method of construction from the parts and units that are not able to perform the overall functional requirements. Modularity means maximum unification of the units and parts, and the maximum possible exception of the intermediate parts, which do not comply with clear functions. In this case, the gearbox is already a module that can be equipped with both automatic and manual control. In its turn, the gearbox module consists of module units: the unit of the planetary range gear with the control element; the gearshift; the units of primary, intermediate and the gearbox main shafts.

2. The source gear-box module differs from all known analogs by the following key features (see Figure 1-2):

- Back support of the gearbox mainshaft is located not in the additional wall of the transmission housing, but in the the cage of the planetary range gear that reduces losses to zero at turning on the highest range of the range gear;

- Back support of the intermediate shaft is also located not in the additional wall, but in the crankcase of the range gear. 


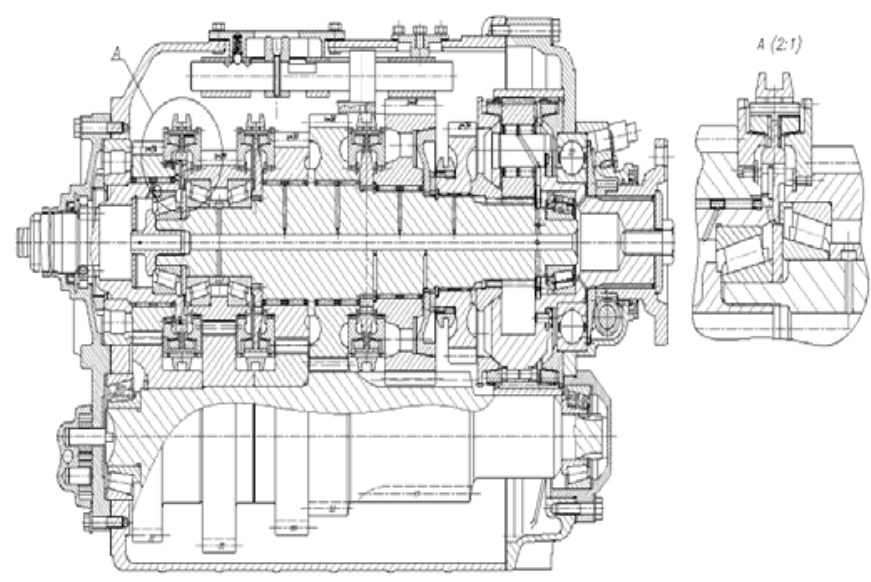

FIGURE I. LONGITUDINAL SECTION OF A TRANSMISSION TM 162000

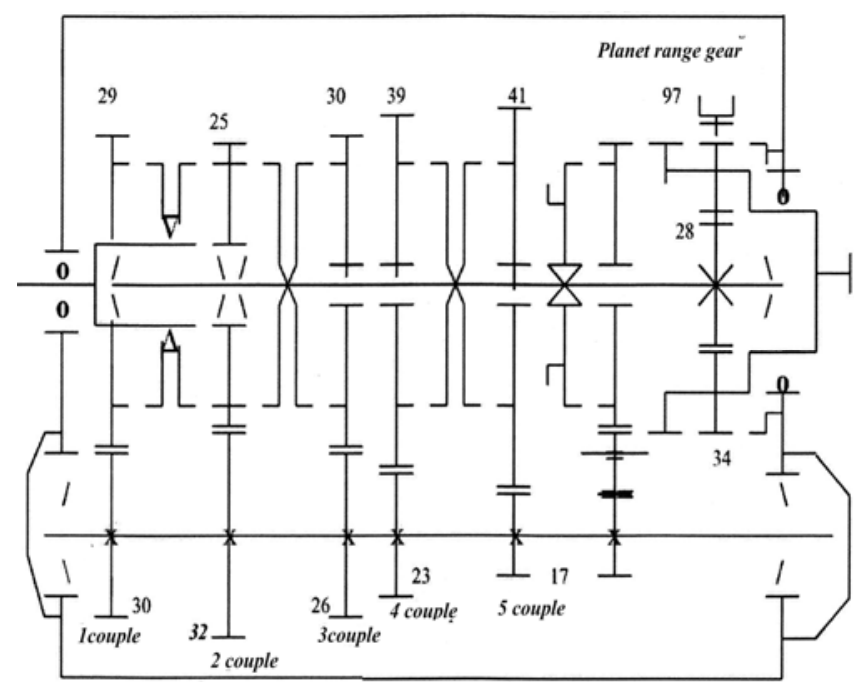

FIGURE II. KINEMATIC DIAGRAM OF THE TRANSMISSION TM162000

This allowed us to have two walls (two body parts) instead of four (three in the housing parts and one of the steel plate) is performed in reverse direction compared to generally accepted one that unloads bearings of the supports and greatly reduces internal losses, as the forward support bearing of the main shaft rotates on a relatively low speed, and the bearing of external supports is much faster.

4. The design feature of the planetary shift stage compared to the widespread solutions is as follows [3]:

- For the range shifting we used the axially movable ring gear with internal teeth, which considerably simplifies the construction of the shifting elements and reduces the overall axial size;

- Blockage of the planetary range gear is carried out when you connect the ring and sun gears. The traditional solution is to block by connecting the ring gear to the carrier. In the locking circuit used in the developed transmission, blockage is achieved 4 times faster; simultaneously it reduces synchronization time when the range gear is shifted from the lowest to the highest range 4-6 times. [3] At the same time the axis of the sun gear and the satellites of the planetary range gear for any misalignment in the process of bending the output shaft are parallel, I. e, they are self-aligning. In the known transmissions their axis are crossed the greater the amount of torque is, not allowing the proper contact pattern on the mating gears and contributing to a reduction of their durability and reliability.

5. In the main gearbox, and the range gear we use compact synchronizers of the coupling type with molybdenum covered blocking rings [5]. Three synchronizers of the main gear are unified. Similar synchronizers are used for planetary range gears. The TM series of boxes on the first gear used to provide additional cone reduction efforts at switching.

The design of synchronizers has the following features:

- Molybdenum consumption is reduced by 3 times by making the spiral grooves not on the molybdenum of the blocking ring, but on the ring gear that does not require expensive and complex process equipment required for processing of high hard molybdenum;

- A fairly time-consuming operation of the synchronizer clamps assembly with coil springs and crackers (9 items all together) is eliminated by using two spring rings;

- At the same time through the use of spring rings we eliminated the need for mating teeth on the couplings to limit the clutch stroke of the coupling that allows us to make the coupling on the universal standard equipment without using special very expensive broaching tools.,

- The design of the locking ring is greatly simplified, only 3 teeth out of 63 have been left;

- The teeth blocking the synchronizer and shifting the gear are separated that maintains the geometry of the locking elements and increases their reliability during the operation;

- The width of the hub is increased to maximum, up to 32 $\mathrm{mm}$ in boxes TM 16-2000, and in the other modifications, that reduces the possibility of self-switching of the transmission.

6. The gearshift mechanism is configured as a separate unit and has the following features:

- It simplifies the structure of the body parts and the assembly of the gearbox;

- It reduces the length of the rods by 2-2.5 times;

- It uses high-tech unified forks made from sheet steel for three synchronizers.

7. In accordance with a pronounced trend observed in the world of automated control systems for manual transmissions, for the whole range of manual transmissions from M6-300 to TM16-3500 the automated control systems are applied. Thus, the following kinds of control are possible [7-12]:

1) Mechanical or pneumatic-mechanical (with servoamplifier)

2) Electro-pneumatic:

2.1) Command (semi-automatic); 


\section{2) Automatic.}

For all modifications of the TM series of gearboxes there is a unified design of the pneumatic- mechanical, and the electropneumatic control, including the main, backup and disaster control unit.

Control of the main gear, splitter and the range gear is performed by means of electro-pneumatic devices, made in the form of independent units. This solenoid controls are mounted directly on the actuators, thereby reducing the required amount of the input air hoses and increase the speed and reliability of the control system.

It should be noted that in the process of work performance we used many years of experience in development of transmission of various dimensions and modifications, as well as control systems. The vast majority of technological and design solutions have been tested in the lab and on road, which ensures reliable operation of the applied constructional solutions and therefore gearboxes in general.

Figure 3 shows the control system of the multispeed manual transmission and the clutch

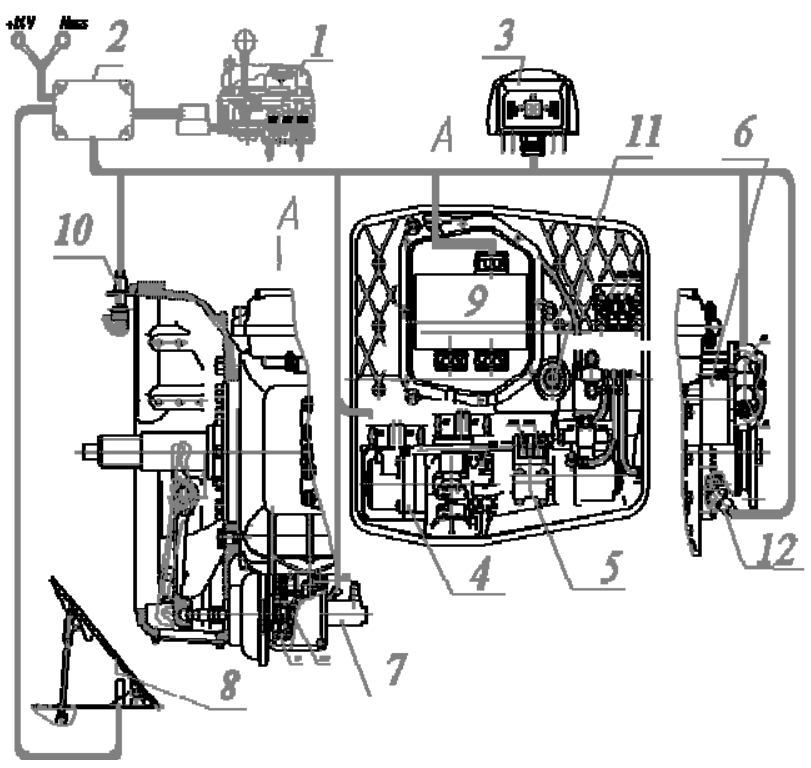

FIGURE III. THE SCHEME OF AUTOMATIC TRANSMISSION AND CLUTCH CONTROL:

1 - THE CONTROLLER; 2 - THE MATCHING UNIT; 3 - THE

MONITOR; 4 - THE MAIN GEAR CONTROL MECHANISM; 5 THE SPLITTER CONTROL MECHANISM; 6 - SPLITTER CONTROL MECHANISM; 7 - THE CLUTCH CONTROL MECHANISM; 8 - THE ACCELERATOR PEDAL; 9 - THE ECU 10 - THE ENGINE SPEED SENSOR; 11, 12 - THE INTERMEDIATE AND OUTPUT SHAFT SPEED SENSOR

\section{THE RESULTS OF LABORATORY BENCH TESTING}

We have manufactured samples of gearboxes (Figure 4) with a manual, semi-automatic and automatic control $[1,2,6$, 7], We've carried out a full range of functional bench tests. We've completed long-run bench tests equivalent to 700,000 kilometers.

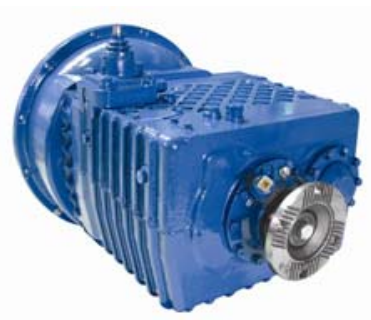

A)

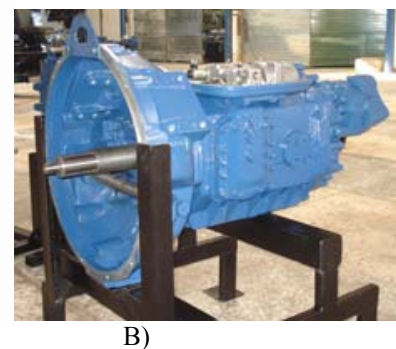

B)
FIGURE IV. EXPERIMENTAL SAMPLES OF GEARBOXES: A) M6-700 B) TM8-2000

Experimental studies were carried out on a special stand for testing transmissions with automatic and command control, manufactured in the NNSTU named after R. E. Alekseev (Figure 5) [7-12]. The stand allows studying the efficiency of the units of manual transmissions (the clutch, the divider, the main reduction gear box, the splitter, definition of the unit efficiency, study of the synchronization process, etc.) and mechatronic control systems for automatic or semi-automatic modes as.

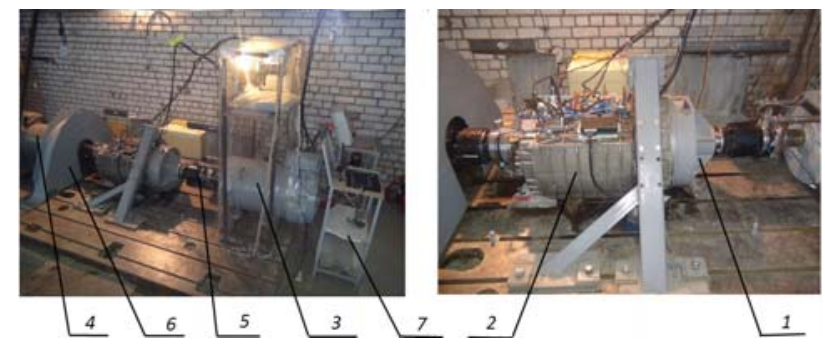

FIGURE V. THE APPEARANCE OF THE STAND FOR TESTING TM162000 TRANSMISSIONS WITH AUTOMATIC CONTROL 1 - THE CLUTCH MECHANISM 2 - THE STUDIED MULTISTAGE TRANSMISSION;

3 - THE DRIVE MOTOR; 4 - THE LOADING MOTOR; 5 -THE DRIVELINE; 6 - THE INERTIAL MASS; 7 -THE REMOTE CONTROL

The studies were carried out on the test bench at the command and automatic modes at alternating pressure in the pneumatic system, different frequencies of rotation of the primary shaft and different values of diameter of the solenoid valve nozzle. Figure 6 shows the results of the experimental studies.

The studies were carried out on the test stand at the command and automatic modes at alternating pressure in the pneumatic system, different frequencies of rotation of the primary shaft and different values of diameter of the solenoid valve nozzle. Figure 6 shows the results of the experimental studies.

Figure 7 shows the results of experimental studies of sixteen staged transmission TM 16-2000 with experimental samples of the automatic and command drive control in the following sequence 2-4-6-8. A signal from the microswitch of gears of the main gearbox is represented at channel №1, a signal from the pressure sensor in the accelerating mechanism of the clutch control is represented at channel №2, a signal from the pressure sensor in the power chamber of the clutch control mechanism is represented at channel №3 and a signal 
from the microswitch of the clutch mechanism is represented at channel №4. It is important to note that in the developed automatic transmissions the gearshift is always performed with the automatic clutch control (channels 2-4, Figure 7).

According to the experimental studies we determined the main parameters of the switch-over process: the total turn-on time of the transmission; the clutch on / off time; time of the pressure rise in the power cylinder, the main gearbox, the divider, the splitter; the response time of the main gear mechanism and a divider in the selection and a given transmission; the dynamic moments on the motor shaft and the output shaft of the transmission; the rotational speed of the motor shaft and the output shaft of the transmission.

In addition, we determined the time of the clutch offlon, as one of the main parameters that characterize the quality of the clutch control. These parameters can be determined from Figure 7, channels 2-3. The turn off time on average equals to $0.15 \mathrm{sec}$., and the turn on time equals to $0.30-0.35 \mathrm{sec}$., that is acceptable for heavy commercial trucks and buses.

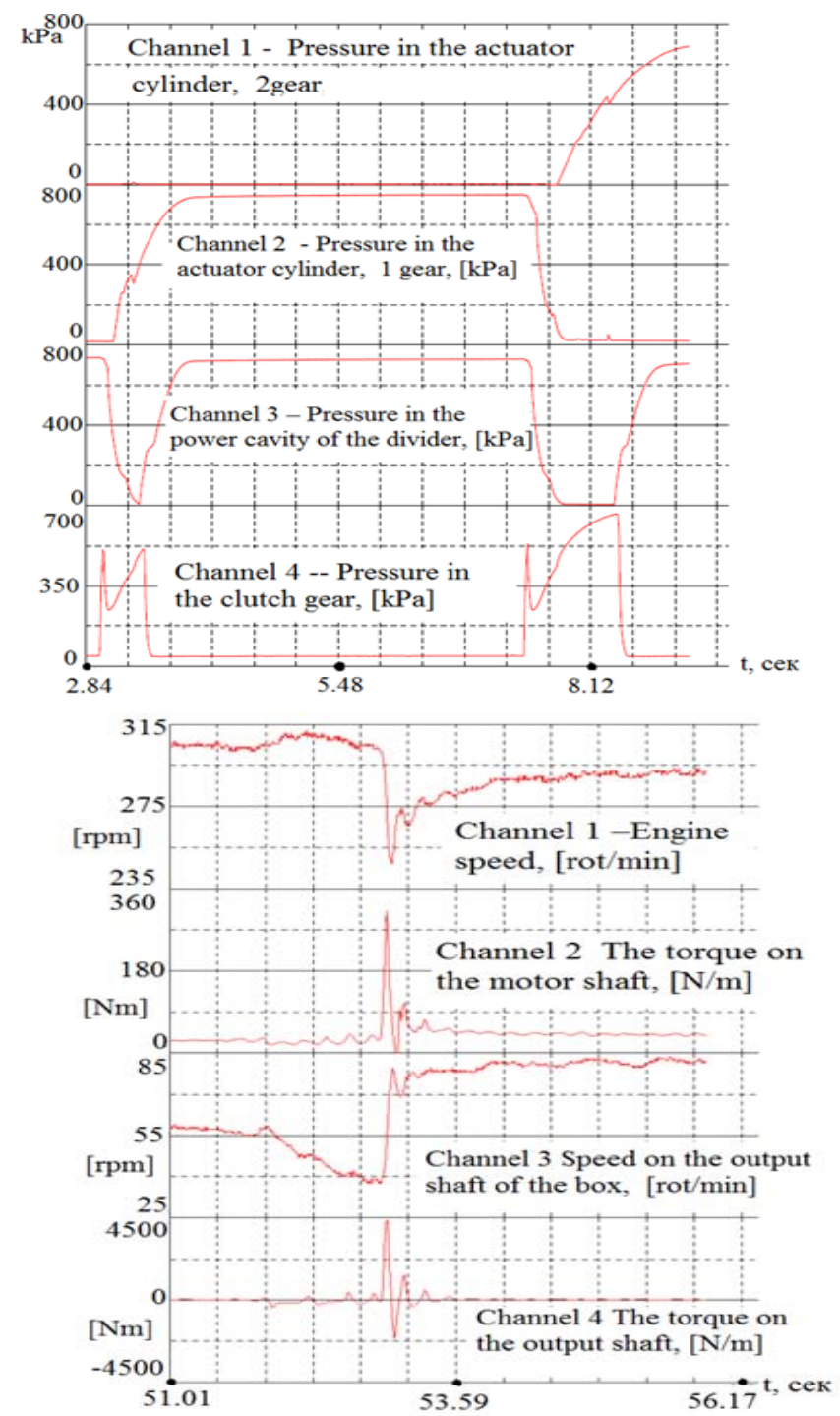

FIGURE VI. THE RESULTS OF THE EXPERIMENTAL STUDIES

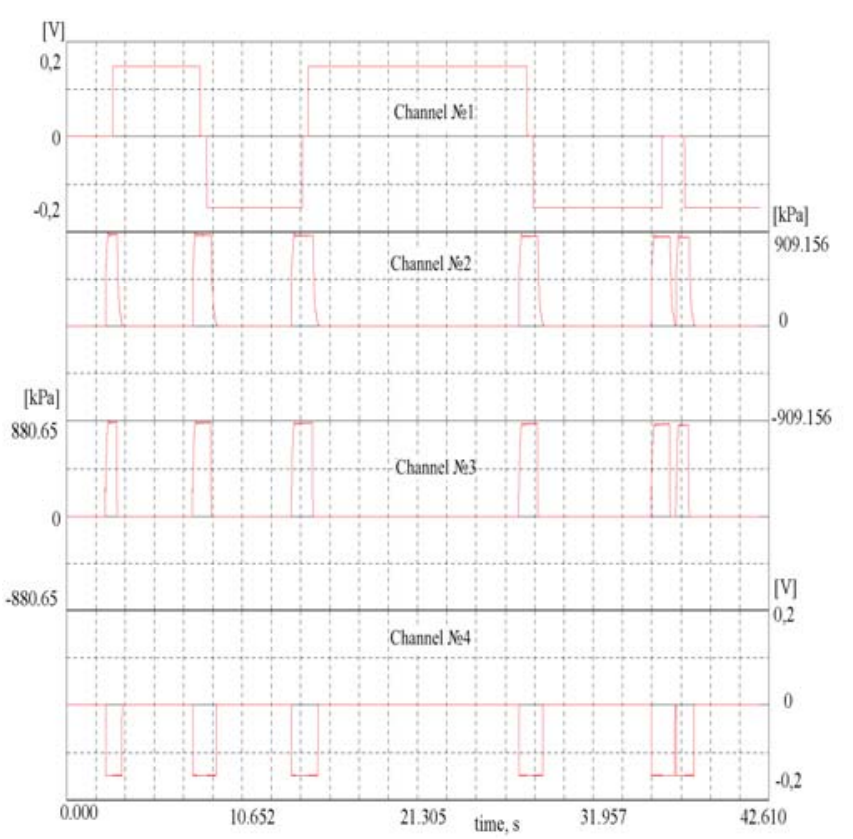

FIGURE VII. - THE EXPERIMENTAL DATA ON THE STAND ON THE PROCESS OF A GEAR SHIFT IN THE TRANSMISSION TM16

Table 2 shows the results of the calculations and the experiments. Calculated values of synchronization time of certain stages and in all cycles of gear shifting differ from the experimental data by $10-25 \%$ maximum.

TABLE II. RESULTS OF THE EXPERIMENTAL AND CALCULATED VALUES OF THE SYNCHRONIZATION TIME

TYPE OF LUBRICATION OIL - MC-20, TEMPERATURE - 325-3350K. TURNOVER OF THE SECONDARY SHAFT N2 $=0$ EQUIVALENT MOMENT OF INERTIA INCLUDING TRANSMISSIONS - Y1 $=0,472 \mathrm{NM}^{*}$ SEC2

\begin{tabular}{|c|c|c|c|c|c|c|c|c|c|}
\hline № & $\begin{array}{c}\text { Resul } \\
\text { t } \\
\text { Exper } \\
\text { iment } \\
\quad / \\
\text { Calcu } \\
\text { lation }\end{array}$ & $\begin{array}{c}\text { Pressu } \\
\text { re } \\
\text { value, } \\
{\left[\mathrm{N} / \mathrm{m}^{2}\right]}\end{array}$ & $\begin{array}{c}\text { Rotation } \\
\text { al speed } \\
\text { of the } \\
\text { input } \\
\text { shaft } \mathbf{n}_{1}, \\
{\left[\begin{array}{c}\text { rot } / \mathrm{min} \\
]\end{array}\right.}\end{array}$ & $\begin{array}{c}\text { Nozzl } \\
e \\
\text { diame } \\
\text { ter d, } \\
{\left[\mathbf{m}^{2}\right]}\end{array}$ & \begin{tabular}{|c} 
Time- \\
to- \\
contact \\
friction \\
cones, \\
{$[s]$} \\
\end{tabular} & \begin{tabular}{|c|} 
Sync \\
hroni \\
zatio \\
n \\
time \\
in \\
critic \\
al \\
disch \\
arge \\
zone, \\
{$[s]$}
\end{tabular} & $\begin{array}{c}\text { Synchr } \\
\text { onizatio } \\
\text { n time } \\
\text { in the } \\
\text { subcriti } \\
\text { cal } \\
\text { dischar } \\
\text { ge } \\
\text { zone } \\
\text { [s] }\end{array}$ & \begin{tabular}{|c} 
Synchr \\
onizatio \\
n time \\
in the \\
zone of \\
constan \\
$t$ \\
pressur \\
e, [s]
\end{tabular} & $\begin{array}{c} \\
\text { Total } \\
\text { synch } \\
\text { roniz } \\
\text { ation } \\
\text { time, } \\
{[s]}\end{array}$ \\
\hline 1 & \multirow{3}{*}{ Exp. } & \multirow{4}{*}{$6.2 \cdot 10^{5}$} & \multirow{4}{*}{2000} & \multirow{4}{*}{$2 \cdot 10^{-3}$} & 0.17 & \multirow{4}{*}[0]{} & \multirow{4}{*}{0.29} & \multirow{4}{*}{0.6} & 0.79 \\
\hline 2 & & & & & 0.18 & & & & 0.83 \\
\hline 3 & & & & & 0.18 & & & & 0.82 \\
\hline 4 & Calc. & & & & 0.18 & & & & 0.89 \\
\hline 5 & \multirow{3}{*}{ Exp. } & \multirow{4}{*}{$7.9 \cdot 10^{5}$} & \multirow{4}{*}{1060} & \multirow{4}{*}{$2 \cdot 10^{-3}$} & 0.13 & \multirow{4}{*}{0.04} & \multirow{4}{*}{0.30} & \multirow{4}{*}{0.033} & 0.36 \\
\hline 6 & & & & & 0.14 & & & & 0.35 \\
\hline 7 & & & & & 0,13 & & & & 0.33 \\
\hline 8 & Calc. & & & & 0.14 & & & & 0.34 \\
\hline 9 & Exp. & \multirow{2}{*}{$9.4 \cdot 10^{5}$} & \multirow{2}{*}{2600} & \multirow{2}{*}{$4 \cdot 10^{-3}$} & 0.04 & \multirow{2}{*}{0.034} & \multirow{2}{*}{0.14} & \multirow{2}{*}{0.335} & 0.51 \\
\hline 10 & Calc. & & & & 0.058 & & & & 0.51 \\
\hline
\end{tabular}

\section{CONCLUSION}

1. The paper analyses the main trends in the development of mechanical staged gearboxes, on the basis of which we developed advanced standard series of manual gearboxes with automated control. . 
2. It presents the characteristics of advanced manual gearboxes from the developed standard series for automobiles, road trains and heavy trucks with engines ranging from 75 to $750 \mathrm{~kW}(100$ to $1,000 \mathrm{hp})$ in the torque range from 360 to 3500 $\mathrm{Nm}$.

3. It considers the basic design features of the unified technical multistage gearboxes on the basis of the leading technology solutions. We've found out that considering the number of gears of synchronized stages, transmitted maximum torque, power, range, density, number of gear ratios, and massdimensional parameters the gearboxes from the standard series rank with the best world analogues.

4. The paper contains a schematic diagram of automatic or command control of the developed multi-staged manual transmissions with microprocessor control.

5. It represents the results of experimental studies on the specialized stand, as well as comparison of theoretical and experimental data. The discrepancy between the data is max. $10-25 \%$.

\section{ACKNOWLEDGEMENTS}

It should be noted that the this work was carried out at the NNSTU named after R.E. Alekseev, with financial support from the government in the face of the Russian Ministry of Education under the Federal Program "Research and development on priority directions of the scientifictechnological complex of Russia for 2014-2020, the unique identifier of the project: RFMEFI57414X0040.

\section{REFERENCES}

[1] A. P. Nedyalkov, The use of advanced technical solutions when creating mechanical staged transmissions with automated control. / A. P. Nedyalkov, A. N. Blokhin // technomag.edu.ru: Science and Education: electronic science and technology publication. - 2011. - №2. URL http://technomag.edu.ru/doc/165381.html

[2] A. N. Blokhin, Innovative transmissions "KOM-NAMI" with mechanical and automated control. / A.N. Blokhin, V. V. Mankovsky, A. P. Nedyalkov // technomag.edu.ru: Science and Education: electronic science and technology publication. - 2011. - №9. URL http://technomag.edu.ru/doc/214551.html

[3] Nedyalkov, A.P. Analytical study of options for kinematic patterns of multispeed planetary rangegears and the choice of optimal parameters of planetary mechanism. / Nedyalkov A.P., Aleksandrov E.B., Blokhin A.N. // Bulletin of the Izhevsk State Technical University. - 2011. - № 2 (50). - p. 39-43.

[4] Nedyalkov, A. P. The method to calculate parameters of an inertial camfree synchronizer with a ring spring element. / Nedyalkov A.P., Trikoz A.A., Blokhin A.N., // "Journal of AAE." Journal of the Association of Automotive Engineers. - 2011. - № 2 (67). - p. 22-25.

[5] A.P. Nedyalkov, Standard series of advanced unified multisynchronized transmissions with automated control. / A.P. Nedyalkov, A.N. Blokhin, V.Y. Tumreev // Actual questions of Mechanical Engineering. Collection of scientific papers. Issue 1 - Minsk: AMI NAS of Belarus, 2012. - S. 216-221, ISSN2306-3084.

[6] Blokhin, A. Perspective dimension-types range of mechanical multispeed gearboxes with automatic control system. / A. Blokhin, A. Tumasov, A. Nedyalkov, V. Mankovsky // Proceedings of 2012 International Conference on Advanced Vehicle Technologies and Integration (VTI 2012), July 16-19 2012, Changchun, China, pp.480484, ISBN 978-7-111-39909-4

[7] A.N. Blokhin, The results of stand tests of sixteen speed transmission with automatic control. / A.N. Blokhin A.P. Nedyalkov, A.E. Kropp // technomag.edu.ru: Education \& Science: electronic science and technology publication. "- $2013 . \quad$ - №12. http://technomag.edu.ru/doc/671097.html.

[8] A.N. Blokhin, The results of computational and experimental studies of efficiency of the multistage mechanical transmission with automatic control / AN Blokhin AP Nedyalkov, AV Tumasov, AM Sox // Actual questions of Mechanical Engineering. Collection of scientific papers. Issue 2 - Minsk: AMI NAS of Belarus, 2013. - S. 171-178, ISSN2306308.

[9] A. N. Blokhin Process modeling of the transmission with multispeed pneumatic drive clutch control- "Actual problems of Engineering" collection of scientific papers, MI NAS Berarus Minsk, 2014, pp. 139143.

[10] A. N. Blokhin, A. P. Nedyalkov Development and evaluation of performance electro-pneumatic clutch control mechanism of the vehicle - "Mechanics and Control Processes" volume 2 Materials of the XXXXIV All-Russian symposium on the 90th anniversary of academician V. P. Makeyev, - M.: Russian Academy of Sciences, 2014 pages 51-62.

[11] A. Blokhin, E. Denisenko, A. Kropp, A. Nedyalkov. The Study of the Synchronization Process in the Gearbox with Automatic Control// Applied Mechanics and Materials Vol. 763 (2015) pp 71-77.

[12] A. Blokhin, S. Dobryaev, A. Plekhov, V. Titov. Electromechanical Complex of Test Loading Stand of Multistage Transmissionswith Automatic Control // Applied Mechanics and Materials Vol. 763 (2015) pp 78-85. 